\title{
The Effect of Physical Activity on Social Physique Anxiety and Academic Achievement in the 8th Grade Secondary School Students
}

\author{
Ufuk Alpkaya \\ Faculty of Sport Sciences, Marmara University, İstanbul, Turkey
}

Copyright $(2019$ by authors, all rights reserved. Authors agree that this article remains permanently open access under the terms of the Creative Commons Attribution License 4.0 International License

\begin{abstract}
The purpose of this study was to analyze the relationship between the level of physical activity, social physique anxiety, and academic achievement. This study evaluated 524 students in total from four schools in İstanbul province, 272 of whom were female and 252 were male students. In order to determine the level of physical activity of students, Physical Activity Questionnaire for Older Children (PAQ-C), developed by Kowalski et al., was used. Validity and reliability of the scale for Turkish population was tested by Sert and Temel. As for establishing the levels of social physique anxiety of students, the scale of Social Physique Anxiety, developed by Hart et al. and adapted to the Turkish society by Doğan was used. For the statistical analyses, averages of the level of physical activity, social physique anxiety, and school academic score were taken. By using Pearson correlation coefficient, the relationship between the averages was checked and the level of significance was set at $\mathrm{p}<0.05$. The results show that, irrespective of gender difference, there is a relationship between physical activity and social physique anxiety $(\mathrm{r}=-.227 ; \mathrm{p}<0.01)$ and between physical activity and academic achievement $(\mathrm{r}=.103 ; \mathrm{p}<0.05)$. When the gender difference is taken into account, there is a relationship between physical activity and social physique anxiety $(\mathrm{r}=-.171 ; \mathrm{p}<0.01)$ and between physical activity and academic achievement for females $(r=.207 ; \mathrm{p}<0.01)$. For males, there is a relationship between physical activity and social physique anxiety $(\mathrm{r}=-.247 ; \mathrm{p}<0.01)$, but there is no relationship between physical activity and academic achievement $(\mathrm{r}=.083 ; \mathrm{p}>0.05)$.
\end{abstract}

Keywords Physical Activity, Social Physique Anxiety, Academic Achievement

\section{Introduction}

Physical activity is defined as the body movements that are caused by the contraction of the skeletal muscles and resulting in energy expenditure [1,2]. Physical activity includes doing light, moderate, and vigorous intensity activities regularly as part of one's daily life. The performance of regular physical activity can be remarkably beneficial to long-term physiological and psychological well-being $[3,4]$. One of the methods that people use in order to give shape to their bodies and have an ideal body form is physical activity and exercise [5]. Physical appearance has been important in people's lives throughout history. In many different social environments where people interact, physical appearances have been in the forefront. Especially in the western culture, slender body shape for women and muscular body shape for males are considered attractive and desirable [6].

One of the essential characteristics of adolescence is that the adolescents are extremely attentive to their appearance. With the impact of environmental factors, appearance becomes very important during this period [7,8]. Apart from people's self-awareness of their bodies, how others perceive them is also important. The anxiety felt by people while their physical appearances are evaluated by others is described as social physique anxiety [4,9].

While the social physique anxiety is expressed as the individual's definition of himself in terms of his physical structure like body fat, muscular structure and body proportions [10], social physique anxiety is expressed to be the result of the individuals' negative perceptions and evaluations of their own bodily image and appearances [6,9,11]. The American Psychiatric Association [12] defines social physique anxiety as a psychological disorder with social environment having an important impact especially on obese females. According to Sabiston et al. (13) social physique anxiety experiences have been related to physical activity participation motives, attitudes, preferences, perceptions of self and ability, and engagement in or avoidance of physical activity

The researchers conducting research on the effect of sports and exercise on the social physique anxiety state that 
the individuals who are engaged in sports and exercise tend to have less social physique anxiety than those who are not $[14,15]$. Again some studies point at a negative correlation between the body image and physical activity $[5,16,17]$ and physical activity and social physique anxiety $(4,18)$. Some researchers disagree with this view and indicate that there is no such correlation $[10,19,20]$. Starting from these researches, our study will look into the effect of physical activity, whether positive or negative, on social physique anxiety.

Our study also aims to analyze the effect of physical activity on academic achievement. Literature indicates that engaging in physical activity during childhood and adolescence is effective on cognitive functions like concentration, classroom behavior and working memory $[21,22]$.

Developments in the brain functions and cognition of children in relation to physical activity are seen as cornerstones in their academic achievements [23]. First evidence about the direct effects of exercise on the brain has been gathered from research on animals, forming the hypotheses for human neuroscience. Developments in neuroscience show that physical activity improves one's cognitive functions by improving the brain's structure and its functions [24]. Academic achievement is generally considered to be the evaluation of the students through national evaluation tests in a school environment and revealing of their level of achievement [23].

While some studies find a positive correlation between physical activity and academic achievement [21,25-26], some do not find such a relationship [27,28]. Some other studies, on the other hand, note that intensive sports practice, participating in physical education courses or regular physical activity do not affect academic success positively or negatively $[29,30]$. Such a contradiction in evidence may result from the arbitrary evaluation of academic performance by academic and cognitive measures. Keeley and Fox [31] argue that cognitive performance is correlated with psycho-physiological changes in brain function, while academic performance depends not only on cognitive performance, but also on family background and environment, teacher perception, and the quality and quantity of academic teaching.

From a general perspective, it seems that the effects of physical activity on social physique anxiety and academic achievement were done and different conclusions were reached. In this context, this study specifically dealt with $8^{\text {th }}$ grade students and the study aimed at analyzing the impact of physical activity on social physique anxiety and academic achievement.

\section{Materials and Methods}

\subsection{Research Design}

The sample of the study consists of 545 students from four public schools in İstanbul province, Turkey. However, the subjects who filled in the scales incorrectly or did not fill in all the scales were not included in the study. Consequently, 272 female students (age $=13.86, \mathrm{SD}=0.34$ ) and 252 male students (age $=13.84, \mathrm{SD}=0.44$ ), a total of 524 students (age $=13.85, \mathrm{SD}=0.39$ ), were evaluated. Those who are registered athletes at a sports club or members of varsity teams at schools were not included in the study.

Previous to the research, consent of the school administration and parents were obtained. The research was conducted during May of the 2016-2017 academic year. Before the scales were filled in by the students, necessary information was provided and their questions were answered. During the research, the students filled in the physical activity scale on the first day and the social physique anxiety scale on the second day.

The scales filled in by the students were controlled by the researchers, and the ones filled incorrectly or incomplete were left out of the research. Then, the scales included in the evaluation were transferred into electronic format. All the scales were implemented by the researcher.

\subsection{Research Instruments}

\subsubsection{Physical Activity Scale}

In determining the level of physical activity, the Physical Activity Questionnaire for Older Children (PAQ-C), developed by Kowalski et al. [32], was used. The scale's validity and reliability for Turkish people were tested by Sert and Temel [33]. The reliability of the scale was 0.74 and the scale, made up of 10 questions, was a 5-point Likert-type scale. The scale measures the level of physical activity done by the individual during the last seven days. The tenth question of the questionnaire asked whether the individual had any health problems during the last seven days that prevented them from doing physical activity. Those answering this question positively were not included in the research. The lowest score that can be obtained from the scale is 9 , whereas the highest is 45. Cronbach's Alpha reliability coefficient for this scale is 0.79 .

\subsubsection{Social Physique Anxiety Scale}

In order to determine the social physique anxiety levels of the students, the Social Physique Anxiety Scale, developed by Hart et. al. [34], was used. The validity and reliability of the scale for the Turkish population was tested by Doğan [35]. Cronbach's Alpha reliability coefficient for Turkey is 0.85 . The scale is a 5 -point Likert-type scale, made up of 16 items. The lowest score one can get from the scale is 16 , whereas the highest is 80 . Scores between 16-37 indicate low level anxiety, while 38-39 are moderate, and 60-80 are high level anxiety. It is assumed that the higher the score obtained from the scale, 
the higher the social physique anxiety is. According to the evaluation system of the scale (never, almost never, sometimes, often, very often), a point between 1 and 5 is obtained. For this sample, Cronbach's Alpha reliability coefficient is 0.87 .

\subsubsection{Academic Achievement}

The scores obtained by the students in the exam organized nationally by the Ministry of National Education in the 2016-2017 academic year, called Transition from Primary to Secondary Education Exam, were taken as academic achievement scores. Exams cover subjects such as science, mathematics, Turkish language, history of revolution, religion, and foreign language. In these exams, the student's test score is evaluated out of 100. The test scores of the students were obtained from the school administrations.

\subsection{Data Analysis}

For the analysis of the data, first normal distribution test was done. Since the skewness-kurtosis value was between $-1.5+1.5$ it was considered to be a normal distribution [36]. Students' average scores on the physical activity, social physique anxiety and academic achievement scores were taken. Using Pearson correlation coefficient, the relationship between averages was analyzed, while the level of significance was set at $\mathrm{p}<0.05$.

\section{Results}

When the Table 1 is examined, the physical activity level for the whole group is found to be at a medium level with an average score of 24.25. These scores show that the students do not take part in physical activities enough. The social physique anxiety level of the students is found to be low with an average score of 30.64, which means that the students are content with their social appearances. With an average score of 63.94, their academic achievement score is medium. Therefore, it can be said that they are not high achievers. Without gender distinction and for the whole group, there is a negative correlation between physical activity and social appearance anxiety $(\mathrm{p}<0.01 ; \mathrm{r}=-.227)$. Less physical activity means higher social appearance anxiety. There is a positive correlation between physical activity and academic achievement $(\mathrm{p}<0.05 ; \mathrm{r}=.103)$. As the physical activity increases, so does academic achievement.

When the Table 2 is examined, the physical activity level for females is found to be 23.19 , which is at medium level, and this score indicates that female students do not participate in physical activities enough. The social appearance anxiety level of the students is found to be low with an average score of 31.96 , which shows that the students are content with their social appearances. With an average score of 67.45 , their academic achievement score is medium. Therefore, it can be said that they are not high achievers. For female students, there is a negative correlation between physical activity and social appearance anxiety $(\mathrm{p}<0.01 ; \mathrm{r}=-.171)$. As physical activity increases, social appearance anxiety decreases, and there is a positive correlation between physical activity and academic achievement $(\mathrm{p}<0.01 ; \mathrm{r}=.207)$. As the physical activity increases, so does academic achievement.

Table 1. Descriptive statistics and correlations among variables for entire group

\begin{tabular}{ccccccc}
\hline Variables & Range & $\mathrm{M}$ & $\mathrm{SD}$ & (PA) & (SPA) & (AA) \\
\hline Physical Activity (PA) & $9-45$ & 24.25 & 10.04 & 1 & $-.227^{* *}$ & $.103^{*}$ \\
\hline Social Physique Anxiety (SPA) & $16-80$ & 30.64 & 5.60 & & 1 & $-.121^{* *}$ \\
\hline Academic Achievement (AA) & $0-100$ & 63.94 & 20.42 & & & 1 \\
\hline
\end{tabular}

$* \mathrm{p}<0.05, * * \mathrm{p}<0.01$

Table 2. Descriptive statistics and correlations among variables for females

\begin{tabular}{ccccccc}
\hline Variables & Range & M & SD & (PA) & (SPA) & (AA) \\
\hline Physical Activity (PA) & $9-45$ & 23.19 & 9.37 & 1 & $-.171^{* *}$ & $.207^{* *}$ \\
\hline Social Physique Anxiety (SPA) & $16-80$ & 31.96 & 5.73 & & 1 & -.076 \\
\hline Academic Achievement (AA) & $0-100$ & 67.45 & 20.6 & & 1 \\
\hline
\end{tabular}

$* \mathrm{p}<0.05, * * \mathrm{p}<0.01$

Table 3. Descriptive statistics and correlations among variables for males

\begin{tabular}{ccccccc}
\hline Variables & Range & M & SD & (PA) & (SPA) & (AA) \\
\hline Physical Activity (PA) & $9-45$ & 25.41 & 5.73 & 1 & $-.247^{* *}$ & .083 \\
\hline Social Physique Anxiety (SPA) & $16-80$ & 29.25 & 9.37 & & 1 & $-.233^{* *}$ \\
\hline Academic Achievement (AA) & $0-100$ & 60.15 & 20.76 & & 1 \\
\hline
\end{tabular}

$* \mathrm{p}<0.05, * * \mathrm{p}<0.01$ 
When the Table 3 is examined, the physical activity level for the males is found to be at a medium level with an average score of 25.41. These scores show that the male students do not take part in physical activities enough. The social physique anxiety level of the students is found to be low with an average score of 29.25 , which means that the male students are content with their social appearances. With an average score of 60.15 , their academic achievement score is medium. Therefore, it can be said that they are not high achievers. For the male students, there is a negative correlation between physical activity and social appearance anxiety $(\mathrm{p}<0.01 ; \mathrm{r}=-.227)$. More physical activity means lower social appearance anxiety. There is a no correlation between physical activity and academic achievement $(\mathrm{p}>0.05 ; \mathrm{r}=.083)$. Physical activity does not seem to have an effect of the academic achievement of the male students.

\section{Conclusions and Discussion}

This study analyzed the relationship between physical activity, social physique anxiety, and academic achievement for the 8th grade students. When the results were analyzed for the whole group, or the group divided as boys and girls according to gender difference, a negative correlation was found between the level of physical activity and social physique anxiety $(\mathrm{P}<0.01)$. As the physical activity of the students increases, their social physique anxiety decreases. When these results are compared to those of other researchers, they seem to be similar $(5,17,37,38)$. According to the conclusion of our study, the adolescents with low social physique anxiety have enough motivation to take part in physical activities and they can be said to have overcome the internal or external barriers. The reason for the increase in physical activity and the decrease social physique anxiety can be the students' desire to gain favor. That is to say, the governments' placing emphasis on health and physical activity for the whole society, broadcasting programs by using television and social media may have increased the awareness level of the students about this issue. This awareness may have given rise to a desire in them to derive physiological, psychological, and physical benefits by participating in physical activities. It has been observed that individuals with high levels of social physique anxiety tend to stay away from environments related to physical activity and fitness (13), as they are anxious of their physical appearances and do not want their physical appearances to be judged by others $(4,19)$.

When we took the gender difference into account in our study, physical activity scores were found to be at a medium level. When the result is considered health wise, the level of physical activity is not sufficient for adolescents $(1,3)$ While we were forming our hypothesis in our study, we assumed that the levels of the physical activity for the individuals with the low levels of social physique anxiety would be high or very high. However, our study shows that even the medium level of physical activity decreases social physique anxiety. It is also possible that our subject group came to participate in physical activities as girls and boys with the expectation that they would benefit from it in terms of their physical appearance. Neumark-Sztainer et al. (2006) found statistically meaningful relation between body satisfaction and physical activity in girls (15). Contributions of other researchers, who interpret the relation between social physique anxiety and physical activity from other perspectives, also seem important (39-41). Kantanista et al. (39) stated that some people tended to shun away from participating physical activities since they felt themselves inadequate because of their either obese or skinny physical appearances. Wertheim and Paxton (2012) state that adolescent girls are more eager to be thinner and prone by using methods other than physical exercise to reach that goal, which are unhealthy and not very effective. With the onset of adolescence, there is a significant increase in body dissatisfaction particularly in the females (41).

When the other dimension of our study, that is the relationship between physical activity and academic achievement is considered, a correlation was found between physical activity and academic achievement $(\mathrm{p}<0.05)$, irrespective of gender difference. Literature indicates that those who are not engaged in sports or regular physical activities have lower academic achievement scores in comparison to those who are engaged in sports or regular physical activities [24,29,42]. These studies show parallels with ours. In their study, Coe et al. [30] point out that academic achievement is correlated only with vigorous activities and not with moderate ones. As an opposing view, Morales et al. [21] stated that in the levels of physical activities that require different energy expenditure, high and moderate level active groups showed a greater academic achievement than the group with lower level of activity.

Developments in the brain functions and cognition of children in relation to physical activity are seen as cornerstones in their academic achievements [23]. It is noted that regular physical activity is thought to effect cognitive development through cerebral blood flow, improve nerve-hormone balance, regulate nutritional habits, and increase neural transmittance $[24,25,43]$. Under the light of these findings of literature, it can be said that an increase in the participation of children and adolescents in physical activities will positively affect their academic achievement.

When gender difference was taken into account in our study, a relation was found between physical activity and academic achievement for boys. On the other hand, no such correlation between physical activity and academic achievement was found for girls. 
It is interesting that different results were reached for the males and the females. The reason for our results being different for the males and the females can be that academic achievement, as Seyfried argues [44], is not only related to cognitive performance, but it could also be influenced by factors like family background, teacher perception, and the quality of academic teaching.

There are some limitations in the present study that should be considered. The results cannot explicitly illuminate the mechanisms that link physical activity, social physique anxiety and academic achievement. The students' conditions of physical activity and social physique anxiety were evaluated on the basis of their responses to the questionnaire, and their responses were considered to be true. Especially for the physical activity questionnaire, the students were asked to write down the activities during the past week; that is, they were asked to remember the last seven days. Therefore, there is a risk of making mistakes. Besides, the factors about the subject group, such as their proximity to sports and recreation areas, how they get to school, quality of education at school, and the socio-economic level of their parents were not included in the study.

Different conclusions reached by many studies focusing on the relationship between physical activity, social physique anxiety, and academic achievement might be due to the scope of the study. Therefore, it can be thought that further studies with the participation of larger groups of subjects and including factors like environmental conditions, educational level, and the socio-economic levels of parents should be put forth. Future research should also aim to provide better understandings of the mechanisms through which physical activity influences academic achievement and social physique anxiety both in the short and long-term.

\section{REFERENCES}

[1] D.S. Ward, R.P. Saunders, R.R. Pate. Physical activity Interventions in Children and Adolescents. Human Kinetics US. pp. 3-21, 2007.

[2] O. F. Keleş, U. Alpkaya. Orta Okul Öğrencilerinin Düzenli Sportif Aktivite ve Okul Başarı Puanlarının Karşılaştırılması. Marmara Üniversitesi Spor Bilimleri Dergisi, Marmara University Journal of Sport Science 1(2); 31-36, 2016.

[3] S. N. Blair, J. N. Morris. Healthy hearts - and the universal benefits of being physically active: Physical activity and health. Annals of Epidemiology, 19(4), 253-256, 2009.

[4] N. P. Kowalski, P. R. Crocker, K. C. Kowalski. Physical self and physical activity relationships in college women: Does social physique anxiety moderate effects? Research Quarterly for Exercise and Sport, 72(1), 55-62, 2001.

[5] C. Fountoulakis, S. Grogan. An investigation of the links between body image and exercise participation. Sport
\&Exercise Psychology Review, 10, 19-30, 2014.

[6] E. H. Wertheim, S.J. Paxton. Body image development Adolescent girls. In T. F. Cash (Ed.), Encyclopedia of body image and human appearance (pp. 187-194). London, UK / San Diego, CA: Academic Press / Elsevier, 2012.

[7] T. Doğan. Sosyal görünüş kaygısı ölçeği’nin psikometrik özelliklerinin ergenlerden oluşan bir örneklemde incelenmesi [An investigation of the psychometric properties of the social appearance anxiety scale in an adolescent sample]. Elementary Education Online, 10(1), 12-19, 2011.

[8] J. Devís-Devís, V. J. Beltrán-Carrillo, C. Peiró-Velert. Exploring socio-ecological factors influencing active and inactive Spanish students in years 12 and 13. Sport, Education and Society 20:3, 361-380, 2015.

[9] E.A. Hart M.R. Leary W.J. Rejeski. The measurement of social physique anxiety. Journal of Sport and Exercise Psychology, 11: 94-104, 1989.

[10] S. Crawford, R. C. Eklund. Social physique anxiety, reasons for exercise, and attitudes toward exercise settings. Journal of Sport and Exercise Psychology, 16 (1), 70-82, 1994.

[11] T. Cash, L. Smolak. Body image: A handbook of science, practice, and prevention. NY: Guilford Press, 2011.

[12] American Psychiatric Association. Diagnostic and statistical manual of mental disorders (5th ed.). Arlington, VA: American Psychiatric Publishing. 2013.

[13] C. M. Sabiston, E. Pila, G. Pinsonnault-Bilodeau \& A.E. Cox. Social physique anxiety experiences in physical activity: a comprehensive synthesis of research studies focused on measurement, theory, and predictors and outcomes. International Review of Sport and Exercise Psychology, 7:1, 158-183, 2014.

[14] P. R. E. Crocker, J. Snyder, K. Kowalski, S. Hoar. Don't let me be fat or physically incompetent! The relationship between physical self-concept and social physique anxiety in Canadian high performance female adolescent athletes. Avante, 6, 1-8, 2000.

[15] D. Neumark-Sztainer, S J. Paxton, P. J. Hannan, M. Stat, J. Haines, M. Story. Does Body Satisfaction Matter? Five-year Longitudinal Associations between Body Satisfaction and Health Behaviors in Adolescent Females and Males. Journal of Adolescent Health 39, 244-251, 2006.

[16] E. Finne, J. Bucksch, T. Lampert, P. Kolip. Age, puberty, body dissatisfaction, and physical activity decline in adolescents. Results of the German Health Interview and Examination Survey (KiGGS). The International Journal of Behavioral Nutrition and Physical Activity, 8, 119. 2011.

[17] H. Kołoło, M. Guszkowska, J. Mazur, A Dzielska. Self-efficacy, self-esteem and body image as psychological determinants of 15-year-old adolescents' physical activity levels. Human Movement, 13, 264-270, 2012.

[18] J. Brunet, C. M. Sabiston. Social physique anxiety and physical activity: A self-determination theory perspective. Psychology of Sport and Exercise, 10, 329-335, 2009.

[19] A. E. Cox, S. Ullrich-French, J. Madonia, K. Witty.). Social physique anxiety in physical education: Social contextual factors and links to motivation and behavior. Psychology of 
Sport and Exercise, 12, 555-562, 2011

[20] L. Melbye, G. Tenenbaum, R. Eklund. Self-objectification and exercise behaviors: The mediating role of social physique anxiety. Journal of Applied Biobehavioral Research, 12, 196-220, 2008.

[21] J. Morales, M. Pellicer-Chenoll, X. García-Masso, M Gomis, L. Gonzales. Relation between physical activity and academic performance in 3rd-year secondary education students. Percept Mot Skills; 113(2):539-546, 2011.

[22] K. Kamijo, N.A. Khan Pontifex MB et al. The relation of adiposity to cognitive control and scholastic achievement in preadolescent children. Obesity; 20(12):2406-2411, 2012.

[23] J. E. Donnelly, C. H. Hillman, D. Castelli, J. L. Etnier, S. Lee, P. Tomporowski, K. Lambourne, A N. Szabo-Reed. Physical Activity, Fitness, Cognitive Function, and Academic Achievement in Children: A Systematic Review. Medicine Science in Sports and Exercise. 48(6): 1197-1222, 2017.

[24] F. Trudeau, R.J. Shephard: (2008) Physical education, school physical activity, school sports and academic performance. International Journal of Behavioral Nutrition and Physical Activity, 5:10.

[25] C. K. Fox, D.B. Anderson, D.N. Melaniewall. Physical Activity and Sports Team Participation: Associations With Academic Outcomes in Middle School and High School Students. Journal of School Health 80(1): 31-37, 2010.

[26] D.I. Rees, JJ Sabia. Sports participation and academic performance: evidence from the National Longitudinal Study of Adolescent Health. Econ Educ Rev; 29(5):751-759, 2010.

[27] M. T. Kantomaa, T.H. Tammelin, P. Demakakos. Physical activity, emotional and behavioural problems, maternal education and self-reported educational performance of adolescents. Health Education Research; 25(2):368-379, 2010 .

[28] U.Y. Dagli. Recess and reading achievement of early childhood students in public schools. Education Policy Analysis Archives.; 20:1-24, 2012

[29] A. Kristjansson, I. Sigfusdottir, J. Allegrante. Health behavior and academic achievement among adolescents: the relative contribution of dietary habits, physical activity, body mass index, and self-esteem. Health Education Behaviour; 37(1):51-64, 2010.

[30] P.D. Coe, J.M. Pivarnik, J.C. Womack, M.W. Reeves, R.M. Malına.. Effect of Physical Education and Activity Levels on Academic Achievement in Children. Official Journal of the American College of Sports Medicine 1515 - 1519, 2006.

[31] J.H. Keeley, K.R. Fox. The impact of physical activity and fitness on academic achievement and cognitive performance in children. International Review in Sport Exercise and Psychologia. 2(2):198-214. 2009.

[32] K.C. Kowalski, P.R.E. Crocker, R. M. Donen. The Physical Activity Questionnaire for Older Children (PAQ-C) and Adolescents (PAQ-A) Manual. College of Kinesiology University of Saskatchewan, 2004.

[33] Z.E. Sert, A. B. Temel. İlköğretim Öğrencileri İçin Fiziksel
Aktivite Soru Formunun Türk Toplumuna Uyarlanmas1: Geçerlilik Ve Güvenilirlik Çalışması. DEUHYO ED, 7(2), 109-114, 2014.

[34] T. A. Hart, D. B. Mora, S. A. Palyo, D. M. Fresco, C. Holle, R. G. Heimberg. Development and examination of the social appearance anxiety scale. Assessment, 15(1), 48-59, 2008.

[35] T. Doğan, Sosyal görünüş kaygısı ölçeğinin Türkçeye uyarlaması: Geçerlik ve güvenilirlik çalışması [Adaptation of the social appearance anxiety scale (SAAS) to Turkish: A validity and reliability study]. Hacettepe University Journal of Education Faculty, 39, 151-159, 2010

[36] B.G. Tabachnick, L.S. Fidell. Using Multivariate Statistics (sixth ed.) Pearson, Boston, 2013.

[37] C. Greenleaf. Weight pressures and social physique anxiety among collegiate synchronized skaters. Journal of Sport Behaviour, 27, 260-276., 2004.

[38] J. J. Reel, D. L. Gill. Slim enough to swim? Weight pressures for competitive swimmers and coaching implications. The Sport Journal, 4. Retrieved from http://www.thesportjourna 1.org/article/slim-enough-swim-weight-pressures-competiti ve-swimmers-and-coaching-implications, 2001.

[39] A. Kantanista W. Osinski, J. Borowiec, M. Tomczak, M. Król-Zielinska. Body image, BMI, and physical activity in girls and boys aged 14-16 years. Body Image. 15 (2015) 4043,2015 .

[40] A. Campbell, H.A. Hausenblas. Effects of exercise interventions on body image: Ameta-analysis. Journal of Health Psychology, 14, 780-793, 2009.

[41] M.P. Levine, L. Smolak. Body image development in adolescence. In T. F. Cash, \& T. Pruzinsky (Eds.), Body image: A handbook of theory, research and clinical practice (pp. 74-82). New York: The Guilford Press, 2002.

[42] G. Saygılı, E. Atay, M. Eraslan, M. Hekim. Düzenli Olarak Spor Yapan ve Yapmayan Öğrencilerin Kişilik Özellikleri ile Akademik Başarıları Arasındaki İlişkinin İncelenmesi. Kastamonu Eğitim Dergisi. 23;1. 161-170, 2015.

[43] Ishihara, T., Sugasawa, S., Matsuda, Y., \& Mizuno, M. Relationship between sports experience and executive function in 6-12-year-old children: Independence from physical fitness and moderation by gender. Developmental Science, 14, e12555. 2017

[44] S.F. Seyfried. Academic achievement of African American preadolescents: the influence of teacher perceptions. Am J Community Psychol; 26(3):381-402, 1998. 